\title{
Função judiciária da glória e da nuvem nos conflitos de liderança no deserto
}

Vicente Artuso

A glória e a nuvem aparecem no contexto de conflito da liderança de Moisés e Aarão com a comunidade no deserto, após a revelação da Lei no Sinai (Nm 16,16-24 e 17, 6-15). O sinal da presença de Deus como juiz é a glória acompanhada pela nuvem, expressão simbólica da vinda de Deus envolto em seu mistério (cf. Nm 10,11-12) ${ }^{1}$. Das cem vezes que "anan", ("nuvem") se encontra no Antigo Testamento, cerca de setenta vezes aparece ligada às aparições e intervenções do Senhor com sua glória ${ }^{2}$. De fato kavod, ("glória") é a palavra que se encontra com a nuvem nos textos sacerdotais (Ex 16,10; 24,15-18; 40,34-38; Nm 9,15-23; 10,11-12,34). Há também os textos que relatam somente a aparição da glória, mas se subentende também a presença da nuvem (Nm 14,10; 16,19; Lv 9,6.23) ${ }^{3}$.

"A nuvem indica a transcendência e a imanência de Deus. Ao cobrir a tenda, também oculta aquele que a enche com sua glória aí presente" ${ }^{\text {. }}$. Por isso, em Nm 17,7, a presença da nuvem que cobre a tenda do encontro é paralela ao aparecimento da glória do Senhor (cf. Ex 24,10; 40,34-38; Nm 10,11-12). Deus surge no céu, "na nuvem", que desce diante da porta

\footnotetext{
${ }^{1}$ Cf. AUZOU, G. Dalla servitù al servizio. Bologna: Edizioni Dehoniane, 1988, p. 187.

${ }^{2}$ Cf. AUZOU, G. Dalla servitù al servizio, p. 185.

${ }^{3}$ Cf. LUZÁRRAGA, J. Las tradiciones de la Nube en la Bíblia, Roma: Pontifício Instituto Bíblico, 1973, p. 15-41.

${ }^{4}$ LUZÁRRAGA, J. Las tradiciones de la Nube en la Bíblia, p. 151.
} 
da "tenda do encontro", local em que se revela a glória de Deus, que também se comunica com o povo (cf. Ex 29,43; 33,7).

Queremos destacar no presente estudo que a aparição da nuvem e a glória, especialmente em textos após a revelação do Sinai, tem função de castigar os revoltosos. Nesse sentido, bastante significativa é a história da revolta de Coré, Datã e Abiram (Nm 16) que enfatiza a derrota e castigo dos revoltosos como tivessem se revoltado contra o Senhor pelo simples fato de contestarem a autoridade de Moisés e Aarão (Nm 16,3-4). Essa história acaba por enfatizar a autoridade de Aarão ( $\mathrm{Nm} \mathrm{17),} \mathrm{como} \mathrm{o} \mathrm{único} \mathrm{que} \mathrm{poderá} \mathrm{se}$ aproximar para oficiar na tenda do encontro e oferecer o incenso para expiar os pecados do povo. Quando a glória de Deus apareceu, se fez ameaça de castigo iminente dos revoltosos contra Moisés e Aarão. De forma semelhante a história em que Aarão e Miriam (Nm 12) murmuram contra Moisés, o texto acaba por enaltecer a figura de Moisés como mediador, o mais humilde que falava com Deus face a face. Quando a nuvem apareceu subitamente Mirian viu-se coberta de lepra. Portanto especialmente nesses textos a revelação da glória e da nuvem tem função judiciária de sentenciar o castigo contra os rebeldes. É a revolta dos líderes e do povo que faz aparecer a glória e a nuvem, como sinais da ira de Deus e seu julgamento. A análise mais detalhada de Nm 16,16-24 com Nm 17,6-15, permite perceber melhor o motivo da aparição da glória e da nuvem ${ }^{6}$

Temos aí uma história de revolta e castigo dos culpados com o gênero literário de aparição da glória do Senhor que vem julgar. Os elementos essenciais são retomados da revolta de Coré e seus companheiros, seguidos da aparição divina em vista do julgamento dos revoltosos (Nm 16,19a.19b-22):

a) murmuração e revolta $(17,6-7$ a e 16,19a);

b) aparição da glória na tenda (17,7c e 16,19b);

c) ordens do Senhor a Moisés em vista do julgamento (17,10ab. e 16,21.24);

d) Intervenção de Moisés e Aarão (17,11.12 e 16,22);

e) execução das ordens do Senhor (17,12 e 16,25-27a $)^{7}$.

O elemento que faz a diferença fundamental em 17,6-15 é a forma da intervenção de Moisés e Aarão. Em 16,22, bastou uma oração de intercessão para salvar a congregação do castigo, enquanto em 17,12, foi necessário o

\footnotetext{
${ }^{5}$ Cf. VON RAD, G. Teologia do Antigo Testamento. São Paulo: ASTE, 1973 vol. 1, p. 235.

${ }^{6}$ Para uma análise de Nm 16-17, cf. ARTUSO, V., A revolta de Coré, Datã e Abiram. Análise estilístico-narrativa e interpretação. São Paulo: Paulinas, 2008, especialmente às pp. 257-283.

${ }^{7}$ Conforme a crítica das fontes, Nm 17,6-15 pode ser um desenvolvimento da camada sacerdotal de Nm 16,19-24 (cf. DE VAULX, J. Les Nombres, Paris: J. Gabalda et Cie Éditeurs, 1972 p. 198). As semelhanças entre os dois textos revelam a origem de uma fonte comum.
} 
rito da expiação realizado por Aarão para fazer cessar a praga. Na revolta de Coré, Datã e Abiram, Moisés e Aarão haviam intercedido apenas pela congregação inocente $(16,22)$; enquanto na revolta de toda a congregação dos filhos de Israel (17,6-7), a intervenção de Aarão faz cessar a praga que estava caindo sobre todo o povo que havia murmurado e se revoltado contra eles $(17,13.15 b)$.

A comparação a seguir entre Nm 17,7-10 e 16,19-22 apresenta com mais detalhes os elementos comuns ${ }^{8}$. São "dois momentos de crise formulados na mais estreita correspondência, seguidos da aparição da glória do Senhor":

1- "Enquanto a congregação se reunia "Coré fez reunir contra eles (Moisés e contra Moisés e contra Aarão" (17,7a). Aarão) toda a congregação" (16,19a).

2- "E apareceu a glória do Senhor" "E apareceu a glória do Senhor a toda $(17,7 \mathrm{~d})$. congregação" (16,19b).

3- "Então falou o Senhor a Moisés "Então falou o Senhor a Moisés e Aadizendo" (17,9a).

4- "Erguei-vos do meio desta congre- "Separai-vos do meio desta congregagação" $\left(17,10^{a}\right)$. ção" (16,21a).

5- "E eu os aniquilarei no mesmo ins- "E eu os aniquilarei no mesmo instantante" $(17,10 \mathrm{~b})$

6- "Então caíram sobre as suas faces" "Então caíram sobre as suas faces" $(17,10 \mathrm{c})$. $(16,22 a)$

A narração da revolta crescente com o envolvimento de maior número de pessoas mostra que o julgamento de Deus é também proporcional à extensão da revolta.

A análise mostra que alguns elementos da revolta de Coré, Datã e Abiram, em Nm 16,1-35, são retomados em Nm 17,6-15, em vista de mostrar que a revolta e também o julgamento do Senhor se expandiram atingindo grande parte da população. A narração inicia com o verbo murmurar: "E murmurou toda a congregação dos filhos de Israel" (v. 6a). A seguir temos a queixa do povo contra Moisés e contra Aarão: "Vós fizestes morrer o povo do Senhor" (v. 6b).

A acusação tem estilo enfático ao iniciar com o pronome de segunda pessoa masculino plural "vós". O conteúdo da fala de toda a congregação revela a gravidade da acusação e evoca outras queixas do passado (Nm 14,2; 16,3).

\footnotetext{
${ }^{8}$ ARTUSO, V. A revolta de Coré Datã e Abiram, p.259-260

${ }^{9}$ BLUM, E. Studien Zur Komposition des Pentateuch, p. 268. O autor coloca em paralelo os dois textos em hebraico, sem maiores comentários das semelhanças e diferenças. Nossa análise mostra que Nm 17,7-10 está articulado com a revolta de Coré, Datã e Abiram, como parte da unidade literária de $\mathrm{Nm}$ 16-17.
} 
Prosseguindo a narração, o autor retoma o verbo "reunir-se contra" (v. 7a. 16,3a.) em uma frase circunstancial, com o sentido de uma ação repetida no passado: "E enquanto se reunia a congregação contra Moisés e contra Aarão" (v. 7a) ${ }^{10}$. Justamente nesse momento é relatado que a nuvem cobriu a tenda do encontro, e a glória do Senhor apareceu (cf. v.7cd).

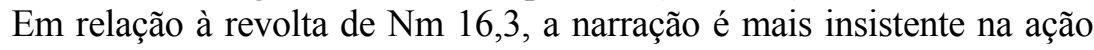
da revolta, ao repetir que o movimento da congregação foi "contra Moisés e contra Aarão" (17,6a.7a). Também a frase temporal com o infinitivo construído como ação repetida no passado indica a freqüência das rebeliões contra as lideranças: "Enquanto se reunia a congregação contra Moisés e contra Aarão" (v.7a). Então a nuvem cobriu a tenda do encontro e apareceu a glória do Senhor (v.7cd). O aparecimento da nuvem que cobriu a tenda do encontro, seguida do aparecimento da glória, é o elemento novo da aparição divina que ocorre imediatamente à formação da revolta ${ }^{11}$.

A sucessão rápida desses fatos revela que o tempo da história também aqui é mais veloz em vista do julgamento que também é veloz. Com efeito, o castigo pode acontecer imediatamente após a separação de Moisés e Aarão (v. 10b).

Outro aspecto em relação à revolta anterior de Coré, Datã, e Abiram é o aumento dos revoltosos. Da revolta dos grupos de Coré, Datã, Abiram e os duzentos e cinqüenta (16,1-3), o autor passa rapidamente (no dia seguinte) à revolta de toda congregação contra Moisés e contra Aarão (17,6-7). Os motivos da revolta de Coré, Datã e Abiram eram variados, reunindo grupos com interesses diversos contra Moisés e Aarão (cf.16,1-15). Agora o motivo da queixa da congregação é único, e mais grave: "vós fizestes morrer o povo do Senhor" (17,6b). O castigo que atingira o grupo dos revoltosos Coré, Datã e Abiram e os duzentos e cinqüenta líderes (16,31-35) agora atinge toda a população, causando grande mortandade. A intervenção de Moisés e Aarão foi a forma de intercessão em favor da congregação $(16,22 \mathrm{~cd})$. Esta fora salva do castigo mediante a separação dos revoltosos (16,21-27). No segundo relato apenas Moisés e Aarão recebem ordens de separar-se, pois todo povo revoltado está sujeito ao castigo (17,10ab). Não basta uma intercessão de Moisés e

\footnotetext{
${ }^{10}$ A frase circunstancial tem função explanatória (cf. LAMBDIN, Thomas O. Introduction to Biblical Hebrew. London: Darton, Longman \& Todd Limited, 1973, p. 164, n. 132). O autor quer lembrar os leitores de que a temática dominante do enredo é o tema da revolta contra Moisés e contra Aarão.

${ }^{11}$ Aqui o verbo reunir da raiz kahal ("reunir") no infinitivo construto precedido da preposição "be" indica a inclusão de uma ação no tempo de outra. (cf. JOÜON, P. Grammaire de L' Hebreu Biblique, Roma: Pontifício Istituto Bíblico, 1921, p. 510, n. 1661). A simultaneidade do aparecimento da glória com o início da revolta do povo indica que o julgamento era implacável contra qualquer espécie de rebelião contra as autoridades.
} 
Aarão que antes impedira que toda a congregação fosse castigada; exige-se agora um rito de expiação a ser realizado somente por Aarão $(17,11)$. Fica claro que a revelação da glória de Deus resultou em benefício dos líderes para protege-los e legitimá-los no poder, à custa da ameaça e castigo do povo.

\section{O aparecimento da nuvem e a glória do Senhor em $\mathrm{Nm} \mathrm{17,7b.d)}$}

O sinal da presença de Deus como juiz é a glória acompanhada pela nuvem, expressão simbólica da vinda de Deus envolto em seu mistério (cf. Nm $10,11-12)^{12}$.

A aparição divina em nosso texto (17,7a.) dá-se no momento em que o povo se reúne contra Moisés e Aarão. Por isso o aparecimento da glória do Senhor no contexto de conflito mantém sua função judiciária no enredo, em vista de aniquilar os revoltosos e assegurar o culto representado na tenda do encontro $(17,8)$ e no altar $(17,11 \mathrm{c})$. O Senhor com toda sua glória aparece como juiz e age a partir da tenda do encontro para trazer a solução dos conflitos $(\mathrm{Nm} 14,10 ; 16,19 ; 20,6)^{13}$. Nesse sentido a nuvem que cobre a tenda do encontro junto à glória do Senhor $(\mathrm{Nm} \mathrm{17,7)}$ é, sobretudo, um lugar revelador (Ex 25,22; Nm 7,89) com uma função oracular.

Da nuvem sai a sentença do julgamento dos revoltosos: "Eu os aniquilarei no mesmo instante" $(17,10 \mathrm{~b})^{14}$. O castigo sobre o povo vem proclamado $(16,21 ; 17,10 b)$ em decorrência das murmurações e revoltas. Outra função da nuvem é proteger a tenda do encontro ${ }^{15}$, diante da qual Moisés veio com Aarão $(17,8)$. A presença de ambos diante da tenda é paralela à outra narração cúltica, em Nm 16,18-19 na qual o povo foi convocado "para a entrada da tenda do encontro" com Moisés e Aarão. Esses textos recordam outras situações em que a nuvem baixava junto da tenda (Ex 33,9-10; Nm 12,5; Dt 31,15). Aqui, a nuvem sobre a tenda tem função protetora, especialmente de Moisés e Aarão ameaçados pela revolta de toda a congregação que investiu contra eles $(17,7 \mathrm{~b})$. O povo virou-se para a tenda do encontro $(17,7 \mathrm{~b})$ como gesto de revolta contra seus líderes ${ }^{16}$. Daí a função da nuvem que, além de cobrir a

\footnotetext{
${ }^{12}$ Cf. AUZOU, G. Dalla servitù al servizio. Bologna: Edizioni Dehoniane, 1988, p. 187.

${ }^{13}$ Cf. CRÜSEMANN, F. A Tora. Petrópolis: Vozes, 2002, p. 494; VON RAD, G. Teologia do Antigo Testamento, vol. 1, p. 234-235.

${ }^{14}$ Cf. LUZÁRRAGA, J. Las tradiciones de la Nube em la Bíblia, p. 178-179.

${ }^{15}$ Cf. LUZÁRRAGA, J. Las tradiciones de la Nube em la Bíblia, p. 81 e 180.

${ }^{16}$ Trata-se, pois de um "voltar-se" qualificado. Este sentido parece ser dado pela versão da

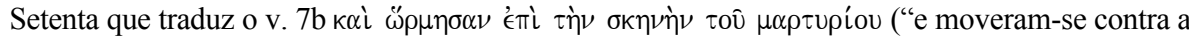
tenda do testemunho") indicando a possível investida do povo contra, pois a preposição є̇ seguida de acusativo significa "contra". A Vulgata coloca os chefes do povo como sujeitos do
} 
tenda e ocultar a glória, protege Moisés e Aarão, legítimos líderes do povo. Esse aparecimento da nuvem sobre a tenda do encontro também para proteger Moisés e Aarão indica a gravidade do conflito.

De fato, a revolta do povo ( $\mathrm{Nm} \mathrm{17,6-7)} \mathrm{revelou-se} \mathrm{mais} \mathrm{violenta,} \mathrm{pelo}$ teor da queixa "vós fizestes morrer o povo do Senhor" e pela necessidade da presença da nuvem protetora da tenda, impedindo uma possível investida dos revoltosos. Moisés e Aarão recebem proteção e instrução, da parte do Senhor, para se afastarem do meio da congregação dos revoltosos. Através da nuvem protetora cobrindo a tenda com Moisés e Aarão, o culto e o sacerdócio recebem também legitimação divina. A potência santificadora da nuvem sobre a habitação a torna extensão do templo como morada do Senhor. A cobertura da nuvem sobre a tenda do encontro recorda a teologia sinaítica de Ex 24,16: "A glória do Senhor pousou sobre o monte Sinai, e a nuvem o cobriu durante seis dias". A tenda é santificada pela nuvem tornando-se templo modelo, como o Sinai $^{17}$. Assim também o culto e o sacerdócio são santificados e recebem sustentação teológica.

\section{A glória do Senhor no êxodo e no deserto}

O termo kavod ("glória") deriva da raiz " $k b d$ ". Como verbo estativo, significa: "ser pesado" ou "tornar-se pesado". A glória do Senhor indica, portanto, o peso, a honra, a influência do nome do Senhor. A glória nesse sentido é a própria manifestação do ser de Deus presente, seu poder sobre o universo, a criação, e a história.

A glória indica que o Senhor pode influir sobre os acontecimentos e dar-lhes novo rumo ${ }^{18}$. Assim o Senhor revela sua glória como poder salvífico na derrota dos egípcios ao passarem o mar (Ex 14,7.17-18), e na peregrinação no deserto, ao dar água (Ex 15,22-25; 17,1-7) e alimento (Ex 16) ao povo ${ }^{19}$.

O aparecimento da glória do Senhor ocorre com freqüência no contexto do Sinai (Ex 24,15-18; 40,34-35; Lv. 9,6.13; 29,43), com objetivo de fundamentar o culto. Para o Sacerdotal, kavod é a revelação da majestade de

verbo voltar-se, ao traduzir: "Moisés et Aaron fugerunt ad tabernáculum foederis". Em nossa interpretação, a congregação é o sujeito de ("viraram-se").

${ }^{17}$ A construção do santuário deveria inspirar-se no modelo mostrado sobre a montanha do Sinai (cf. Ex 25,9.40; 26,30; 27,8; 8,4). Por isso, o autor via no templo o modelo do Sinai, como lugar da presença e revelação do Senhor.

${ }^{18}$ Cf. WESTERMANN, C. כבד ("ser pesado"). In: JENNI, E; WESTERMANN, C. Diccionario Teológico Manual Del Antiguo Testamento I, Madrid: ed. Cristiandad, 1985, c. 1108-1110; EICHRODT, W. Teologia del Antiguo Testamento,Brescia: Paideia, 1972, vol. I, p. 38-39.

${ }^{19}$ Cf. SKA, J. L. Israele nel deserto, Appunti ad uso degli studenti, PIB, 1989, p. 19. 
Deus que Israel encontrou no Sinai. Essa revelação caracteriza o momento fundante do povo de Deus, como assembléia cultual na celebração da Aliança (Ex 24), com a confirmação do culto, do sacrifício, e do sacerdócio como instituições sagradas.

Com a mediação de Moisés, Deus ordena a construção da habitação (Ex 25). Uma vez construída, "a glória de Deus encheu a habitação" (Ex 40,34). Assim é confirmado para Israel o lugar santo (Ex 40,34-35). O santuário por sua vez possibilita a ação sagrada que também é confirmada pela aparição da glória do Senhor (Lv 9,6.23). A glória do Senhor continua a

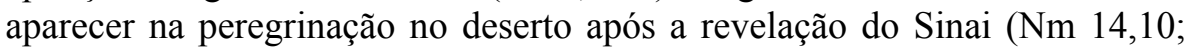
$16,19 ; 17,7 ; 20,6)$.

O aparecimento da glória, muitas vezes acompanhada da nuvem, era o sinal da presença do Senhor com o povo em marcha rumo à terra prometida (cf. Nm 10,11-12; 17,7).

Nos textos de aparições antes do Sinai, o povo não era punido por causa das murmurações e nem os líderes por sua pouca fé (cf. Ex 15,22$27 ; 16 ; 17)$. Nos textos após a revelação do Sinai (Nm 14,10; 16,19; 17,7; 20,6), ao contrário, a aparição da glória do Senhor ocorre nos momentos de confronto para punir os revoltosos e aqueles que murmuram contra o Senhor e contra os seus líderes. Cada um desses textos pós-sinaíticos observa J. L. $\mathrm{Ska}^{20}$, caracteriza-se como relato de pecado e castigo. Deus está presente e requer da parte do povo fidelidade. O pecado do povo é possível depois da revelação do Sinai, porque, a partir de então, o povo aceitou livremente as cláusulas da Aliança e todas as legislações cultuais. As transgressões contra essas leis ou instituições cultuais tornam-se ofensas contra o Senhor ${ }^{21}$. A instituição da autoridade sacerdotal ganha status de Torá revelada e com legitimidade vinda do Senhor. Assim, quando a glória do Senhor aparecia após a revelação do Sinai, nos momentos críticos de conflito, tornava-se então sinal do julgamento de Deus contra os murmuradores e rebeldes (cf. $\mathrm{Nm} 12,5.9-10 ; 14,10)$. Deus, portanto, faz sentir o peso do seu poder e soberania como juiz para punir os culpados ${ }^{22}$. No contexto da teologia sacerdotal, as narrativas da aparição da nuvem e a glória sobre a tenda do encontro se prestam a dar sustentação teológica e aprovação divina à instituição do segundo templo e seu culto centralizado no período pós-exílico.

\footnotetext{
${ }^{20}$ SKA, J. L. Israele nel Deserto, p. 10. Sobre o comportamento que Israel deve seguir após a revelação do Sinai, para escapar da ira do Senhor, cf. SCHART, A. Mose und Israel im Konflikt, p. 236-237.

${ }^{21}$ Cf. WESTERMANN, C. כבד. (“ser pesado"). In: JENNI, E; WESTERMANN, C. Diccionario Teológico Manual Del Antiguo Testamento I, col. 1109.

${ }^{22}$ Cf. WENHAM, G. J. Números. São Paulo: Editora Mundo Cristão, p.1985, p. 128.
} 


\section{A aparição da glória em $\mathrm{Nm} 16,19 b$}

O aparecimento da glória do Senhor, em 16,19b, é melhor compreensível em conexão com as outras aparições no contexto do êxodo e do deserto. A glória de Deus, em 16,19b, apareceu no momento decisivo do enredo, como sinal de sua presença julgadora. Era uma necessidade, pois Moisés já havia invocado o Senhor na segunda cena contra os revoltosos: "Não voltes para a oferta deles" $(16,15 \mathrm{c})$. A forma do jussivo nifal para a aparição da glória expressa a urgência da intervenção do Senhor em vista de revelar suas decisões à congregação que aguarda ${ }^{23}$.

O Senhor coloca-se ao alcance do seu povo, porque a glória aparece a toda congregação na entrada da tenda do encontro (v. 19b). A glória de Deus aparece para revelar que ele está presente e atuante (cf. Ex 25,8) e seu aspecto de honra inclui a aparência de algo que entra pelos olhos. Daí o verbo wayyare' no hebraico (jussivo nifal), "apareceu", "deixou-se ver". Assim a aparição da glória é conteúdo próprio da teofania do Sinai: "A glória do Senhor parecia aos olhos dos filhos de Israel como fogo devorador sobre o cume da montanha" (Ex 24,17). No Levítico, livro situado no contexto do Sinai, a relação entre kavod ("a glória") e a nuvem tormentosa está indicada também pelo fogo que sai da nuvem e devora o sacrifício de Aarão (cf. Lv. 9,6.23-24).

Em nosso texto, o fogo do Senhor também aniquila aqueles que ofere-

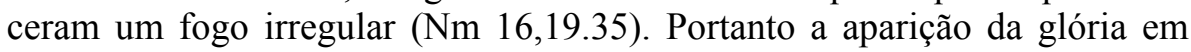
$\mathrm{Nm} \mathrm{16,19a}$., relacionada com a teofania do Sinai, indica o esplendor da presença do Senhor que legitima o julgamento iminente dos rebeldes que ofereceram um fogo irregular e tinham ambição de alcançar o sacerdócio.

O sentido da aparição da glória está associado à habitação (cf. Ex 16,7.10; 29,43; 40,34-35. Lv. 9, 6.23) e, portanto, legitima especialmente o lugar sagrado da presença de Deus, como um novo Sinai. A teologia da aparição e a teologia da presença de Deus estão interligadas ${ }^{24}$. A glória pode manifestar a gratuidade da presença de Deus que protege e guia o povo através da nuvem. Esta, também, algumas vezes é sinal da ira divina e julgamen-

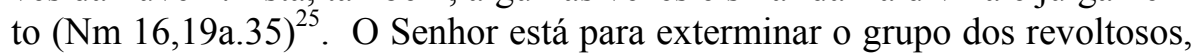
incluídos o grupo de Coré Datã e Abiram e os duzentos e cinqüenta líderes.

\footnotetext{
${ }^{23}$ VON RAD, G. Teologia do Antigo Testamento, vol. 1, p. 238.

${ }^{24}$ Cf. VON RAD, G. Teologia do Antigo Testamento, vol. 1, p. 236. Nessa perspectiva, ganha significado a teologia do sacerdócio eleito, ligado a um lugar de culto.

${ }^{25}$ Sobre os efeitos da aparição da glória, cf. HENTON DAVIES, G. Glory. In: The Interpreter's Dictionary of the Bible, vol. 2, p. 401; EICHRODT, W. Teologia Del Antiguo Testamento, vol. 2, p. 39.
} 
A ordem a Moisés e Aarão de afastar-se da congregação dos revoltosos, desde logo, prepara a ação do juízo final como extermínio. O fogo que normalmente deve consumir os holocaustos (Lv 9,23) como sinal de aceitação, é associado à glória do Senhor como elemento punitivo para queimar um grupo de revoltosos, que também ofereceu um fogo irregular (Nm 16,35). O aspecto da glória do Senhor de fato aparece como um fogo em vista do julgamento (Ex 24,17; cf. Nm 11,1-3). Por outro lado, a glória do Senhor também é sinal de que ele vai aceitar o oferecimento de incenso do grupo de Aarão, como em Lv 9,23: "A glória do Senhor apareceu a todo povo porque o fogo saiu diante do Senhor e consumiu o holocausto e a gordura sobre o altar". A glória do Senhor nesse enredo aparece no momento de crise entre os dois grupos, e de protesto contra as lideranças. Eles denunciam a forma autoritária de Moisés e Aarão liderar (Nm 16, 3.13). Por isso, a glória preanuncia um castigo terrível (Nm 16,21b. cf. Nm 14,10; 16,19 a, 17,7; 20,6) ${ }^{26}$. O Senhor quer consumir toda a congregação em um instante.

Esses julgamentos contra os ímpios demonstram também a santidade de Deus. Somente um grupo privilegiado podia aproximar-se dele ${ }^{27}$, formando um cinturão de proteção e mantendo a ira divina sob controle mediante 0 oferecimento do incenso e sacrifícios de expiação.

\section{Considerações Finais}

À guisa de conclusão pode-se destacar alguns tópicos sobre a presença de Deus. Deus é reconhecido seja na tenda do encontro, na morada, no santuário, no templo, porque ali as pessoas se encontram.

Nos textos que relatam a caminhada do povo depois do Sinai, a presença de Deus algumas vezes é também julgadora diante da dureza de coração daqueles que se rebelam contra Deus e também contra Moisés e Aarão. Em se tratando dos filhos de Israel nos relatos de culpa e castigo, os culpados sempre são punidos porque justamente conhecem a lei revelada no Sinai e que foi transmitida por meio de Moisés. A experiência religiosa tanto é da gratuidade e misericórdia de Deus, como do juízo punitivo de Deus presente nas desgraças e catástrofes naturais. Porém a imagem de Deus que pune aqueles que se revoltam contra Moisés e Aarão (Nm 16-17), provém de tex-

\footnotetext{
${ }^{26}$ Cf. AHUIS, F. Autorität im Umbruch, p. 79; WENHAM, G. J. Números, p. 44.

${ }^{27} \mathrm{Da}$ mesma forma como o Monte Sinai foi cercado, e qualquer pessoa que ultrapassasse os limites seria apedrejada ou flechada (Ex 19,12-13), assim a morada precisava ser separada das tribos que acampavam ao seu redor por um cordão de isolamento composto de sacerdotes e levitas. Estes podiam executar qualquer pessoa não autorizada que se aproximasse $(\mathrm{Nm} \mathrm{1,49-}$ $3,10)$.
} 
tos pós-exílicos, que forjaram uma imagem de Deus ao lado da liderança sacerdotal e insensível às reclamações do povo, bem diferente da verdadeira imagem de Deus do êxodo que ouve o clamor do povo e se compadece (cf. Ex 3,7-8).

Abstraindo alguns textos (cf. em Nm 11;12;16-17; 20-21), as narrativas revelam a presença de Deus bastante positiva. O Senhor é aquele que ouve, cura o povo, dá água, alimento (cf. Ex 15-17). Ele está próximo. É na comunidade reunida na tenda do encontro que o Senhor habita (Ex 25,8). Porém Deus se revela também acima da tenda do encontro. Ele transcende os lugares de culto e as instituições religiosas. O céu é o trono de Deus e a terra é o escabelo dos seus pés (Cf. Is 66,1). "Toda a terra está cheia de sua glória" (Is 6,3). Na tradição profética, Deus se revela acima de tudo por sua Palavra.

A tenda do encontro, a morada de Deus e a revelação de sua glória, revelam que o Senhor, não está distante da história. Ele se faz presente no meio do povo como um Deus pessoal que se comunica. O motivo da revelação de Deus, mais que santificar um lugar, é a comunicação de sua palavra, de seus desígnios. É o que as pessoas buscam, uma palavra, um oráculo. A tenda é montada pelo povo para ser um santuário sagrado de Deus que caminha com eles e os anima nas lutas pela vida. Nesse sentido a construção da tenda ou santuário é também sinal do clamor do povo que reivindica seu lugar, seu espaço, sua liberdade de ter voz, de sentir-se no seu mundo como sua casa. Um exemplo em nosso tempo foi a montagem da "tenda dos mártires" à margem do Rio Paraíba, próximo ao Porto de Itaguaçu, nos dias 13 a 31 de maio de 2007. Assim o teólogo Agenor Brighenti, descreve essa grande tenda: "Era uma grande barraca de lona, decorada com estampas das centenas de mártires latino-americanos, que davam ao local de terra batida um caráter sagrado e convidava a tirar as sandálias e deixar-se contagiar por seu testemunho. Diariamente nesse local havia celebrações, ofício das comunidades, reflexões e missa. Essa iniciativa foi perpassada de mística e profetismo e aconteceu também graças à persistência e apoio de alguns teólogos, Oscar Beozzo, Benedito Ferraro, entre outros. Graças a essa "tenda dos mártires", a outra "tenda do encontro", - a assembléia dos bispos latino americanos em Aparecida -, inseria no Documento final o tema das CEBs, as intuições da teologia latino-americana, e o reconhecimento do testemunho dos mártires das causas sociais como "nossos santos, ainda não canonizados" 28 Muitas Igrejas são espaços de liberdade da expressão religiosa, do culto a Deus, da busca de respostas, e também de reivindicação para participar da

${ }^{28}$ BRIGHENTI, Agenor. Documento de Aparecida. O contexto do texto. In: REB (Revista Eclesiástica Brasileira), Petrópolis, fascículo 268, outubro de 2007, p. 799, nota número 27. 
construção do mundo sonhado, como a grande casa habitável para todos, "uma nova terra" (Ap. 21,1). Porém, a manipulação do espaço sagrado, e a ideologização de textos sagrados, obscurecem a verdadeira imagem de Deus libertador, o Deus da vida. São textos que revelam um Deus ao lado de um pequeno grupo no poder. Se lemos os textos na ótica do povo que sofre e clama por seus direitos à vida, paz e segurança, veremos que o clamor do povo é legítimo pois clama ao Deus verdadeiro. Foi nessa situação de busca, de libertação, que Deus se revelou o que Ele é (Ex 3,14-15) sempre presente ao lado da vida.

Vicente Artuso

Doutor em Teologia Bíblica pela PUC-Rio

É professor adjunto da PUCPR, no Programa de Pós-Graduação em Teologia 